\title{
Knowledge sharing in knowledge-intensive manufacturing firms. An empirical study of its enablers
}

(post-print - final draft post-refereeing)

\section{Authors Details:}

Vincenzo Cavaliere

Associate Professor of Business Organization and Human Resource Management

Department of Economics and Management

University of Florence

Florence

Italy

ORCID ID: 0000-0002-8199-2923

Sara Lombardi

Ph.D. Student in Management

Department of Business and Management

LUISS Guido Carli

Rome

Italy

ORCID ID: 0000-0002-0462-7658

\section{Luca Giustiniano}

Associate Professor of Business Organization

Department of Business and Management

LUISS Guido Carli

Rome

Italy

\&

Visiting Professor

Nova SBE - Nova School of Business and Economics

Lisbon

Portugal

\&

Research Affiliate

ICOA - Interdisciplinary Center for Organizational Architecture

Aarhus University

Aarhus

Denmark

ORCID ID: 0000-0002-3044-6535

Corresponding author: Vincenzo Cavaliere

Corresponding author's Email: vincenzo.cavaliere@unifi.it

Please check this box if you do not wish your email address to be published

\section{Acknowledgments:}

A previous version of the paper was presented at the $13^{\text {th }}$ ECKM (European Conference on Knowledge Management, University of Cartagena, Spain, 6-7 September 2012), and at the 14 ${ }^{\text {th }}$ WOA (Workshop dei Docenti e Ricercatori di Organizzazione Aziendale, the Sapienza University of Rome, 30-31 May 2013). Vincenzo Cavaliere and Sara Lombardi are very thankful to the organizers and the attendants of the two conferences for the very valuable feedback received. Luca Giustiniano is grateful to Børge Obel and to all the members of ICOA for the precious feedback collected during the presentation of the preliminary version of the study.

\section{Biographical Details (if applicable):}

Vincenzo Cavaliere is Associate Professor of Business Organization at the Department of Economics and Management - University of Florence, (Italy).

His research interests include entrepreneurship and organization learning in SMEs, knowledge sharing and strategic human resource management. Recently he created the ICOHRS Research Lab (Innovating \& Changing

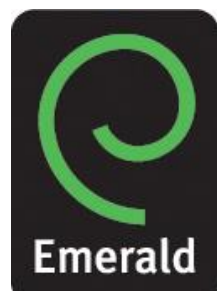


Organizations' and Human Resources' Strategies), a research group of the Department of Economics and Management at the University of Florence. He is member of AOM (Academy of Management), AIDEA (Accademia Italiana di Economia Aziendale), and ASSIOA (Associazione Italiana di Organizzazione Aziendale).

Sara Lombardi is a Ph.D. student in Management at the LUISS Guido Carli University (Rome, Italy).

Her research interests mainly focus on intra-organizational knowledge sharing and utilization processes, employees' learning strategies and the motivational foundations of individuals' behaviors within the organizations.

She also works with Copenaghen Business School - Strategic Management and Globalization Department and she is part of the ICOHRS Research Lab (Innovating \& Changing Organizations' and Human Resources' Strategies), which is a research group created jointly with the Department of Economics and Management at the University of Florence. She is member of AOM (Academy of Management), EURAM (European Academy of Management), and AIDEA (Accademia Italiana di Economia Aziendale).

Luca Giustiniano (PhD in Management - Information Systems) is Associate Professor of Business Organization at the LUISS Guido Carli University (Rome, Italy). During his career he has been visiting scholar at the Viktoria Institute (Sweden, 1999), visiting scholar at the Wharton School of Management, University of Pennsylvania (USA, 2003), and Visiting Associate Professor at the Sauder School of Business, University of British Columbia (Canada, 2011). His research interests are focused on organization design using qualitative, quantitative, and simulative approaches. Being on sabbatical leave for the 2014/15 academic year, he is currently working at the Interdisciplinary Centre for Organizational Architecture (ICOA, Aarhus University, Denmark) and at the Nova School of Business and Economics, Lisbon (Portugal). He is a member of ASSIOA (Associazione Italiana di Organizzazione Aziendale), EGOS (European Group for Organizational Studies), and AOM (Academy of Management).

\section{Structured Abstract:}

\section{Purpose}

Following previous studies, knowledge-sharing (KS) processes consist of knowledge donating (KD) and knowledge collecting (KC). Within this framework, the paper investigates the relationship between KS processes and KS enablers to understand the effect of organizational, individual and technological factors.

\section{Design/methodology/approach}

The study is based on a web survey. Data were collected from a sample of 759 knowledge workers selected from 23 knowledgeintensive manufacturing companies exposed to international markets and located in Tuscany (Italy). The analysis is based on multivariate regression models considering $\mathrm{KD}$ and $\mathrm{KC}$ as dependent variables.

\section{Findings}

The results show that individual, organizational and technological factors matter to KS. Specifically, the paper reports that individuallevel enablers and supportive leadership have a positive effect on both sub-processes of knowledge sharing. Further, the organic management system has a strong and positive impact on knowledge donating, while the efficacy of ICT solutions is positively related to knowledge collecting.

\section{Research limitations/implications}

Although based on a geographically bounded perimeter, the analysis allows some generalizations. In fact, the paper proposes a set of enablers that empirically link micro- and macro-organizational mechanisms to KS.

\section{Practical implications}

The evidence described can help to improve the organizational management of KS and, consequently, support managers dealing with organizational design aimed at successful KS.

\section{Originality/value}

The paper presents original results by combining individual, organizational and technological variables in the explanation of KS. It could be a basis for further studies.

\section{Keywords:}

Knowledge sharing, individual enablers, supportive leadership, organizational structure, organic management systems, self-efficacy.

\section{Article Classification:}

Research paper

For internal production use only

Running Heads: Knowledge sharing in knowledge-intensive manufacturing firms 


\section{Introduction}

\subsection{Background}

The usage of knowledge as a competitive weapon is not new to the field of management. In particular, the growing pressures from the external environment are encouraging companies to exploit their employees' critical knowledge.

To support appropriate knowledge management, managers are paying considerable attention to promoting intra-organizational knowledge sharing as a means of generating competitive value (Pinho et al., 2012; Serenko and Dumay, 2015; Sun, 2010; Zhang and Jiang, 2015). However, improved knowledge sharing requires a delicate equilibrium between voluntary contributions and enabling mechanisms. In this vein, the effectiveness of intra-organizational knowledge sharing (KS) can be investigated through its two fundamental processes of knowledge donating (KD) and knowledge collecting (KC) (Van den Hooff and de Ridder, 2004).

\subsection{Relevance and research gaps}

The extant literature highlights the need to investigate facilitators of knowledge management processes, such as KS processes, by examining individual, organizational and technological factors (Armistead, 1999; Pinho et al., 2012; Rego et al., 2009), as they represent the most relevant domains that are likely to affect knowledge flows. Hence, while information technology allows the sharing of knowledge at a low cost, most of the knowledge management and sharing success depends on both people's behavior and organizationlevel variables (Bhatt, 2001; Pinho et al., 2012; Ruggles, 1998; Thompson, 2005; Vorakulpipat and Rezgui, 2008). Regarding the organizational factors, formalized and centralized organizational structures seem to inhibit the interaction and communication among employees, thereby constraining the exchange of information within the firm (Kim and Lee, 2006). Computer-mediated communication (CMC) tools (Van den Hooff and de Leeuw van Weenen, 2004; Van den Hooff and de Ridder, 2004) and social media (e.g., Bharati et al., 2015) can play an important role in easing that constraint. Further, trust-based relations are hampered by an organizational climate and culture (Chang and Lin, 2015) that stimulates competitive rather than cooperative behaviors (Willem and Scarbrough, 2006), as well as the adoption of self-centered leadership styles by top managers (Håkonsson et al., 2012). As for the individual factors, some studies have shown that enjoyment in helping others enhances KS by magnifying the positive effect of intrinsic motivation (Lin, 2007), while others have focused on the importance of self-efficacy as an instrument to contribute to organizational performance (Wasko and Faraj, 2005). Despite the richness of the literature, the role played by individual, organizational and technological factors in employees' KS behaviors remains unclear and much needs to be uncovered with regard to these relationships.

\subsection{Purpose of the paper and methodology}

Building on this premise, this paper aims to enrich the understanding of how the effect of three main KS enablers triggers KS processes. The main purpose is thus to investigate the role played by individual, organizational and technological (ICT-related) factors as enablers of employees' orientation toward sharing knowledge with others within the same firm. Hence, given the need to foster intra-organizational knowledge exchange processes, the following research questions arise:

R.Q. 1: How can managers intervene to stimulate and intensify the intra-organizational mechanisms of KS? R.Q. 2: What are the individual enablers of KS (including enjoyment in helping others and knowledge selfefficacy)?

R.Q. 3: What are the organizational enablers (including structure and integration mechanisms) of KS?

R.Q. 4: What are the ICT-related enablers of KS? 
Answering these research questions should help to determine which factors are likely to promote or inhibit employees' tendencies to engage in KS. Accordingly, a multivariate regression model was run to analyze web survey data collected from 759 knowledge workers operating in 23 highly innovative, knowledgeintensive (Alvesson, 1993; Starbuck, 1992) and international manufacturing firms.

The paper is organized as follows. Section 2 presents a review of the relevant literature. Theoretical support for the hypotheses is then provided. Section 3 describes the sample selection, the data collection processes and the research method used. Section 4 presents the results of the empirical analysis. Section 5 reports the main elements of the discussion, while Section 6 concludes the paper with managerial implications and directions for future research.

\section{Theoretical background}

\subsection{Knowledge-intensive firms and competitive advantage}

According to Alvesson (1993), a knowledge-intensive organization (KIO) can be defined as "a firm that can produce exceptionally good results through the help of outstanding expertise" (p. 1001). The same definition can be used for knowledge-intensive firms (KIFs), in which knowledge is more important than other inputs (Starbuck, 1992). Therefore, some significant conclusions assume relevance (Starbuck, 1992):

1) A KIF may not be information-intensive or, better, the information intensity could be relevant to the value chain but not characterize the final product (e.g., Porter and Millar, 1985);

2) When deciding whether a firm is knowledge-intensive, "exceptional (technical) expertise must make an important contribution" (p. 716);

3) Expertise can be "broadly" conceived through the inclusion of people (experts) as well as the expertise embedded in machines and routines.

The literature on KIOs and KIFs posits that knowledge is not exclusively embedded in individual people. Knowledge can be found in three concurring domains: individual, organizational and technological.

Building on the resource-based view of the firm (Barney, 1991) and the subsequent knowledge-based perspective (Grant, 1996), the more knowledge is developed, managed and exploited, the more its value increases (Mei et al., 2004; Van Baalen et al., 2005): sharing knowledge becomes a fundamental process that firms should constantly pursue to sustain their competitiveness.

\subsection{The knowledge-sharing process}

In this paper, the authors conceive KS as encapsulating the exchange of both tacit and explicit knowledge. This echoes the difficulty of clearly separating the two types of knowledge, since, as Nonaka's model postulates (Nonaka, 1991), each can be transformed into the other to create new knowledge.

Unlike other organizational behaviors, sharing knowledge requires interplay between at least two parties, who play the role of "sources" and/or "recipients" (Quigley et al., 2007; Van den Hooff and de Leeuw van Weenen, 2004; Van den Hooff and de Ridder, 2004; Zhang and Jiang, 2015), or "sellers" and "buyers" (Reid, 2003), who, while engaging in KS, generate "feedback questions, amplifications, and modifications that add further value for the original sender, creating exponential total growth" (Quinn et al., 1996, p. 8).

In so doing, KS can be seen as a social interaction, which leads employees to exchange work-related experiences and skills with colleagues (Lin, 2007) and to stimulate critical thinking and creativity, thereby nurturing the creation of new knowledge (Nonaka, 1991) and the reduction of learning efforts (Lin, 2007).

This could take place at different levels. Considered at the individual level, KS involves listening and talking to others, sharing solutions, giving the example (tacit knowledge) and, at the same time, learning from others' experience and developing new ideas (Cummings, 2004; Reid, 2003).

Moreover, sharing knowledge with others is seldom a planned behavior (Zhang and Jiang, 2015). Hence, despite scholars usually assuming it to be a relatively stable phenomenon (see, for instance, theory of planned behavior studies, Jeon et al., 2011; theory of reasoned action research, Bock et al., 2005; social exchange literature, Liao, 2008), most knowledge-sharing activities are rather situational, episodic and mostly interpersonal. 


\subsection{Knowledge-sharing sub-processes: knowledge donating and knowledge collecting}

Following the literature, knowledge dissemination can take place through the active communication "to others of what one knows, or actively consulting others in order to learn what they know" (Van den Hooff and de Leeuw van Weenen, 2004, p. 14). That is, knowledge sharing can manifest through two subprocesses (Lin, 2007; Van den Hooff and de Leeuw van Weenen, 2004; Van den Hooff and de Ridder, 2004): knowledge donating (KD) and knowledge collecting (KC). KD expresses employees' willingness to communicate with others and transfer their (pieces of) intellectual capital voluntarily. KC is instead the process of asking colleagues to share their knowledge and, in turn, learning from them. Therefore, knowledge donating refers to a voluntary behavior that employees undertake on their own initiative, while knowledge collecting entails a specific request for information (i.e., knowledge) from colleagues. The complementarity of KD and KC does not imply equality in nature and symmetry. In fact, as recent research has shown (Cavaliere and Lombardi, 2015), such processes are different in nature and can be influenced by different factors (e.g., Van den Hooff and de Ridder, 2004). The importance of investigating both of them is consistent with the aforementioned idea that $\mathrm{KS}$ is often an occasional behavior, which occurs either voluntarily or following a request from others. At the same time, the joint examination of both knowledge donating and knowledge collecting implies the necessary involvement of senders and receivers.

\subsubsection{Knowledge sharing and human behavior}

Investigating knowledge-donating and knowledge-collecting processes parallels the distinction of KS behaviors into two main types, namely proactive and responsive (Zhang and Jiang, 2015), depending on the stimuli that trigger the action of sharing knowledge with others. Proactive KS refers to individual and voluntary exchange of knowledge and ideas with others to obtain feedback and comments on them. As the literature states (Van Dyne and LePine, 1998), proactive behaviors are usually extra-role behaviors and, as such, discretionary. They are performed without a formal requirement from their job description. Differently, responsive KS occurs when knowledge is shared when somebody asks for help and advice. Therefore, in this case, the behavior follows the recipients' action of asking, that is, it results from a prior behavior adopted by others.

\subsection{Knowledge-sharing enablers}

KS enablers are defined as the mechanisms that facilitate employees' KS within a company (Lin, 2007). They are likely to foster individual and organizational learning by enhancing the willingness to share critical information across the organization. Some authors use other terms, such as facilitators (Pinho et al., 2012) or catalysts (Yeh et al., 2006) to indicate positive factors that, if appropriately promoted, can significantly contribute to fostering knowledge management processes, such as KS processes.

The paper investigates the KS processes by considering three different critical enablers: individual, socioorganizational and technological.

\subsubsection{KS individual enablers}

At the individual level, knowledge is often personal and difficult to share without a social exchange involving individuals or teams (Kogut and Zander, 1992; Polanyi, 1958). In this vein, to foster effective sharing of knowledge, organizations must pay attention to individual enablers (Bartol and Srivastava, 2002; Foss et al., 2010; Grodal et al., 2015). 
Following the theory of reasoned action (TRA) (Fishbein and Ajzen, 1975), KS could be explained by individuals' beliefs and attitudes, but also by factors specifically related to human and social exchange processes, which provide a better explanation of human behaviors (Bock et al., 2005; Lin, 2007).

Prior research suggests that the inclination to participate in KS activities depends on a range of individual characteristics, including experience, enjoyment in helping others, motivation, beliefs, self-efficacy and trust (Aulawi et al., 2009; Bock and Kim, 2002; Cabrera et al., 2006; Lin, 2007). Accordingly, by integrating selfdetermination theory (SDT, Deci and Ryan, 1985) into TRA, it can be stated that individuals who perform their task for the pleasure that they gain from it are usually more oriented toward establishing social relationships and sharing knowledge with others. Similarly, those showing a high degree of self-confidence in their own capabilities are expected to be more inclined to engage in KS activities.

The study by Wasko and Faraj (2005), conducted in an electronic community of practice, suggests that individual motivators may increase employees' willingness to share knowledge. Lin (2007) links KS to firm innovation capability, finding that knowledge self-efficacy and enjoyment in helping others facilitate the sharing of knowledge.

Studies at the individual level have been conducted in a number of applied areas. Wang and Noe (2010) offer an interesting systematic review of KS enablers, including research at the individual level. In a more recent publication, Witherspoon et al. (2013) present a meta-analysis on the antecedents of organizational KS.

\subsubsection{Enjoyment in helping others}

The enjoyment in helping others derives from the concept of altruism (Organ, 1988) and is defined as the perception of pleasure obtained from helping others through knowledge contribution. Especially when knowledge is viewed as a public good that is socially generated, maintained and exchanged (Ardichvili et al., 2003; Brown and Duguid, 1991), employees are more likely to desire to support others in solving problems or accomplishing tasks.

Research has recognized the crucial role of intrinsic motivators (i.e., enjoyment in helping others) in explaining knowledge-sharing behavior (Lin, 2007).

Consistent with SDT, Gagné (2009) posits "that intrinsically motivated people will want to share knowledge simply out of their passion for their work and as an expression of themselves" (p. 574). Thus, knowledge workers who enjoy helping colleagues may be more inclined both to donate and to collect knowledge.

\subsubsection{Knowledge self-efficacy}

According to Bandura (1997), knowledge self-efficacy represents the degree to which one judges one's capability to accomplish a certain level of performance. To this extent, individuals are able to control and perform specific tasks and face difficulties and challenges. In addition, the greater the confidence in one's self-efficacy in a context, the greater the satisfaction of belonging to that specific context. Focusing on expertise, the beliefs that experts hold about their capacity to solve problems and to struggle with strains affect individuals' motivation, behaviors and performance.

In the setting of KS and the creation of new knowledge, self-efficacious employees are able to influence their context actively and derive even more satisfaction from it (Bandura, 1997; Judge and Bono, 2001). Moreover, based on self-efficacy theory, Bock and Kim (2002) find that individuals' judgment of their own capabilities to contribute to the organizational performance have a positive effect on their KS attitude.

Following the exposed concepts, the authors posit that:

Hp 1a: Individual enablers are positively related to knowledge-donating behaviors within the organization. Hp 2a: Individual enablers are positively related to knowledge-collecting behaviors within the organization.

\subsubsection{KS organizational enablers}

An appropriate knowledge management activity requires organizations to design their structures adequately to be consistent with both the environment and the necessary level of interaction among employees. The 
organizational enablers of KS can be connected to the "organic form" proposed by Burns and Stalker (1961) - as opposed to the "mechanistic" one, which offers a valid ground to verify the assumptions of this study. The consequent organic management system is also consistent with the lean thinking approach (Womack et al., 1990).

Regarding the organizational enablers, the authors consider the "organic" features as being positively related to intra-organizational KS behaviors as they foster firms' capacity to implement knowledge management practices and a culture of continuous improvement (Staats et al., 2011), thus offering opportunities for social interaction.

In exploring the organic organizational enablers, this work focuses on the presence of the features of the organic structure, a supportive leadership style and the operating procedures.

\subsubsection{The organic form}

An organizational structure that supports openness, intra-organizational creativity and innovation is likely to enhance KS and the creation of a learning environment (Creed and Miles, 1996) in which employees perform a variety of tasks and are engaged in continuous business improvement. The features of the organic form that are more effective for KS are (Burns and Stalker, 1961): the contributive nature of special knowledge and experience to the common task, the shedding of responsibility as a limited field of rights, obligations and methods, the spread of commitment beyond any technical definition, omniscience no longer imputed to the head, lateral rather than vertical directions of communication and content of communication that consists of information and advice. Further, because of the lack of rigid procedures and strict hierarchical control, this highly adaptive form of organization encourages communication and collaboration at all levels within the organization (O'Dell and Grayson, 1998).

\subsubsection{Supportive leadership}

This paper builds on the classification of leadership styles identified by the path-goal theory of leader effectiveness (House, 1971, 1996). Within this framework, leaders can behave in different ways that can be classified as (House and Mitchell, 1974): a) directive, when their behavior is intended to provide subordinates with a psychological structure, b) participative, when it is oriented toward group involvement in decision making, c) supportive, when it aims to satisfy the subordinates' needs and preferences, or d) instrumental, when it is oriented toward the achievement of goals.

Supportive leadership is consistent with the idea of "work facilitation", meant as an organizational condition based on "... providing mentoring, developmental experiences, guidance, coaching, counseling and feedback to assist subordinates in developing the knowledge and skills required ..." (House, 1996, p. 339). It also recalls the "empowering leadership" proposed by Arnold et al. (2000), which is found to have a positive impact on KS (Srivastava et al., 2006). A supportive leadership style can therefore be considered as an enabler of employees' empowerment and an enactor of their actual (perceived) autonomy on the job. In fact, freedom and independence in planning and conducting the job (Hackman and Oldham, 1974) are more likely in an organic management system, in which the lack of rigid means of decision and communication eases employees' engagement in professional life (Deci and Ryan, 2000; Miller, 1983). Led in a supportive way, more self-confident and autonomous employees are more active in $\mathrm{KS}$, due to the fact that they might feel more responsible for their job and, then, more motivated to share their ideas and experiences with colleagues (Cabrera et al., 2006).

\subsubsection{The integration mechanisms}

Integration mechanisms are tools that help to establish communication channels between separated units (Mintzberg, 1979). The previous literature has stressed the importance of task forces (Gupta and Govindarjan, 2000) and multi-functional teams (Meeus et al., 2001), which are more likely in organic and lean structures and, as such, more appropriate for KS. This is consistent with Galbraith's (1974) argument 
that organizational activity often does not follow the vertical hierarchical structure; rather, lateral relations better reflect how organizational coordination activities take place. Formal integrative mechanisms (i.e., organic structure) should facilitate KS because they are intended "to make sure that enough relevant information is available at the right time to be able to make the right decisions" (Burton and Obel, 2004, p. 84).

Following the arguments developed above, the authors hypothesize that:

Hp 1b: Organizational enablers are positively related to knowledge-donating behaviors within the organization.

Hp 2b: Organizational enablers are positively related to knowledge-collecting behaviors within the organization.

\subsection{KS technological enablers}

"Knowledge is a stock of expertise, not a flow of information" (Starbuck, 1992, p. 716), so it also includes know-how and experience (Kogut and Zander, 1992) that cannot be easily transmitted and communicated because of their possible tacitness, which makes them hard to formalize. Further, it is justified by one's belief (Nonaka, 1991; Polanyi, 1958).

Despite the wider scope of knowledge against information, information technology can play a central role in KS. The understanding of such a role as an organizational enabler of KS is rooted in the seminal work on organization design undertaken by Galbraith (1974). "A basic proposition is that the greater the uncertainty of the task, the greater the amount of information that has to be processed between the decision makers during the execution of the tasks. If the task [is not well] understood, then during the task execution more knowledge is acquired, which leads to changes in resource allocation, schedules, and priorities. All these changes require information processing during task performance" (Galbraith, 1974, p. 28). Starting from this point, information and communication technology (ICT) solutions have previously been regarded as mechanisms of organizational interventions (information systems) and tools for group problem solving. They have subsequently been considered as sources of firms' competitive advantage, due to their contribution to the storage and sharing of knowledge (Nonaka, 1991; Porter and Millar, 1985) through the usage of Intranets, groupware, repository systems and collective memories (Alavi and Leidner, 2001; Avgerou et al., 2004; Davenport and Prusak,1998; Hansen, 1999; Hargadon, 1998; Swan et al., 1999; Yeh et al., 2006; Zack, 1999) and later via the sustainment of social media (e.g., Bharati et al., 2015; Kaiser et al., 2007).

\subsubsection{ICT as an enabler of KS}

According to Orlikowski and Gash (1994), ICT tools can be defined as "technological frames", since they embed assumptions, expectations and knowledge that organizational members have regarding technology in their shared (social) contexts. Such a perspective considers technologies as social artifacts with material forms and functions (Avgerou et al., 2004; Huysman and Wulf, 2006; Orlikowski and Gash, 1994; Zaidman and Brock, 2009). As stated by Bhatt (2001): "The conversion between information and knowledge is best accomplished through social actors, but social actors are slow in converting data to information. This is one of the reasons [why] knowledge management is best carried out through the optimization of technological and social systems" (p. 68).

In this fashion, ICT is able to contribute to KS via two main mechanisms: 1) the storage of explicit knowledge and its consequent accessibility and availability (De Long and Fahey, 2000) and 2) a higher level of efficiency in the buyer/seller processes of knowledge transfer (Boland Jr et al., 1994). As recently shown by Del Giudice et al. (2015), despite the almost two decades of ICT development, a winning solution for KS has still to emerge, and different standards are still competing.

\subsubsection{ICT efficacy and ICT use}


The role of ICT solutions as facilitators of $\mathrm{KS}$ is also well documented in knowledge-intensive contexts (Armbrecht et al., 2001; Bharati et al., 2015; Chang and Li, 2007; Giustiniano and Bolici, 2012; Jarle Gressgård et al., 2014; Palvalin et al., 2013; Rego et al., 2009). Following the literature, the perception regarding the role of ICT infrastructures as facilitators of KS can be identified as "ICT efficacy", while the actual usage of them by employees can be labeled "ICT use" (e.g., Lin, 2007; Van den Hooff and de Leeuw van Weenen, 2004; Van den Hooff and de Ridder, 2004).

More recent studies allow a deeper understanding of these organizational facets of ICT. In fact, the range of ICT effects on KS varies from very operational aspects, like the elimination of non-value-adding tasks (Palvalin et al., 2013), to very complex individual initiatives, like employee-driven innovation (Jarle Gressgård et al., 2014).

Further, as recently shown by Bharati et al. (2015), the ICT solutions embedded in social media could favor the enhancement of social capital and, in turn, promote the organizational efforts in knowledge management, eventually affecting the quality of the organizational knowledge. Although the literature seems to support the hypothesis that ICT solutions represent valid support for KS, some further reflections can be made.

\subsubsection{ICT efficacy}

There are several recent pieces of research suggesting that "ICT efficacy" should positively influence either knowledge collecting or knowledge donating, or both. Evanschitzky et al. (2007) show that knowledge management and network management are both crucial for business success. In particular, the task of network management being the establishment of organizational routines and the building and maintenance of meta-knowledge about the existing competencies and abilities (Evanschitzky et al., 2007), the supporting ICT infrastructure should nurture such processes. In fact, from this perspective, each individual may contribute or access knowledge within the network. Further, Cao and Xiang (2012) show how both formal and informal knowledge governance play a key role in KS. To this extent, the availability of a computermediated communication infrastructure could be a significant part of the formal knowledge governance system (e.g., Van den Hooff and de Leeuw van Weenen, 2004; Van den Hooff and de Ridder, 2004). The emphasis on the role of ICT as a vehicle of both knowledge collecting and knowledge donating is also consistent with the assumption that the "appropriation" of the individual knowledge serves neither employees nor organizations, while all the members should be active in the development and management of knowledge (Rechberg and Syed, 2014).

\subsubsection{ICT use}

The positive effect of ICT use upon KS has been shown by several recent studies, focusing both on the intensity of the KS and on the frequency of interactions (Stenius et al., 2015). Sheng et al. (2013) find an interesting moderating role of information communication technology (ICT) competencies in enhancing knowledge transfer in knowledge-intensive organizations. Further, ICT seems to be able to mitigate the effects of two key knowledge barriers: knowledge stickiness and knowledge ambiguity (Sheng et al., 2013). In the same vein, other studies demonstrate that ICT can positively affect KS via information management motivation (IMM), in which "proactiveness" and "formality" enact KC, while "sharing" and "transparency" play a central role in KD (Hwang et al., 2014). This is also consistent with the evidence that proactive KS (see par. 2.3.1) is related to the recipient's professional ability and to the personal relationship with the sharer, and all of them significantly affect the sharer's willingness to donate knowledge (Zhang and Jiang, 2015).

Considering the above-described assumptions, the authors posit that:

Hp 1c: Technological enablers are positively related to knowledge-donating behaviors within the organization. 
Hp 2c: Technological enablers are positively related to knowledge-collecting behaviors within the organization.

The above discussion is summarized in Figure $1 \mathrm{a}$ and Figure $1 \mathrm{~b}$ below.

INSERT FIGURE 1a AND FIGURE 1b ABOUT HERE

\section{Sample selection and research method}

\subsection{Sample selection}

Following Van den Hooff and Huysman (2009), the formulated hypotheses were tested through a webbased survey that involved highly innovative, manufacturing, knowledge-intensive firms, located in the region of Tuscany and operating in international markets. While the overall population was composed of 405 firms, only 23 companies accepted the invitation to contribute to the survey $(5.6 \%$ of the population). Considering the in-depth investigation related to the research questions (see par. 1.3), the companies' voluntary participation was considered a major element of commitment and the reliability of the data (e.g., Schroer and Hertel, 2009).

The focus on manufacturing sectors is related to the fact that the study reported here is part of a broader institutional research project, aiming to understand the distinctive features characterizing such industries, which play an important role in the region's competitiveness. Despite its geographical limitation, the area is representative of the national competitiveness both in absolute terms (impact on GDP) and for the industrial configuration (IRPET, 2014).

\subsection{Pilot questionnaires, involvement of HR directors and sample}

Prior to the running of the survey, a draft questionnaire was pilot tested by 53 managers working for 3 different companies. The acquired feedback was valuable and the first draft of the questionnaire was subsequently revised and tested again with 45 managers. For each of the 23 companies, a meeting with the Human Resource Director was arranged to illustrate the purpose of the study and the relevance of KS. The meetings were also an occasion for identifying the employees to be involved in the survey. In particular, considering the research setting and questions (see Sections 1 and 2), the survey was addressed to those employees who were considered "nodes of knowledge," having a crucial position within the strategic information flows. More specifically, the sample included employees who were directly involved in KS processes as a consequence of possessing critical knowledge related to clients, suppliers, R\&D, markets or specific technical issues. Thus, the study targeted those workers whom Cohen and Levinthal (1990) identify as gatekeepers, standing at the interface of either the firm or the external environment or between organizational subunits, playing a significant role in the absorptive capacity (ability to learn) of the firm. Such workers are the ones who play a relevant role in the "spiral of knowledge creation" proposed by Nonaka (1991), given their ability to translate tacit and explicit knowledge into a form that can be easily acquired or better understood by anyone in the firm, therefore playing a crucial role in supporting KS activities.

\subsection{Sample size}


This version of the paper reports on the following evidence (year 2014): out of the 1,503 invitations to participate in the survey sent out, 759 questionnaires were completed (50.5\% response rate). The average response rate within the companies involved in the study was $74.3 \%(27.6 \%$ the minimum; $100 \%$ the maximum).

\subsection{Measures}

According to Spector (1994), all the variables in the questionnaire were operationalized through selfreported measures. Moreover, all the scales adopted came from previous studies and all of them were multiple-item and seven-point Likert-type scales.

\subsubsection{Dependent variables}

Consistent with the previous literature, Van den Hooff and de Leeuw van Weenen (2004) provide the items used to measure both knowledge donating (KD: three-item scale) and knowledge collecting (KC: four-item scale). The participants in the survey were required to give their opinion with regard to the extent to which they adopt knowledge-sharing behaviors with their colleagues as they learn something new (i.e., KD) and the extent to which they share information with those colleagues who ask for it (i.e., KC).

\subsubsection{Independent variables}

To measure employees' enjoyment in helping others, this study used four items derived from Wasko and Faraj (2000), who analyze employees' perceptions of pleasure obtained through sharing knowledge. Knowledge-self efficacy three-item scale was adopted from Spreitzer (1995) and captured the extent to which employees are confident in their capacity to provide knowledge that others in the firm value.

The organic structure's scale consisted of six items partially adapted from Gold et al. (2001), which measured, among other things, the extent to which the organizational structure promotes collective behavior as well as the extent to which it encourages to innovate and experiment by valuing employees' knowledge. The supportive leadership style is captured through a four-item scale taken from House (1971). Respondents were asked to evaluate how and whether their superior commits himself/herself to making things pleasant at work as well as whether he/she treats all the workers as equals. Operating procedures were measured with a three-item scale adopted from Spector (1985) related to the role that rules play in task accomplishment.

ICT use was measured with two items derived from Lee and Choi (2003), describing the extent to which employees make use of electronic storage to access knowledge in the firm. In turn, ICT efficacy was captured by a seven-item scale drawn from Gold et al. (2001), which asked the respondents to indicate whether, in their opinion, ICT facilities really provide job productivity and effectiveness and make it easier to cooperate with others both inside and outside the organization.

\subsubsection{Control variables}

In the analysis, the control variables included the employees' age, gender (dummy variable for which $0=$ male, $1=$ female), education level (measured as years of education), tenure (measured as years spent within the firm) and managerial role (whether the respondents play a coordinating role by having responsibility for their collaborators' performance; dummy variable for which $0=$ no, $1=y e s$ ).

\section{Findings}

\subsection{Correlations, reliability and regression models}


The descriptive statistics, correlation matrix and Cronbach's alphas are reported in Table 1a and Table 1b. Considering the scope and setting of this study, the internal consistency reliability is considered to be above the recommended levels (Cascio, 2012), having just one explanatory variable (out of seven) with $\alpha=.64$, with .60 being the acceptable "criterion in use" (Peterson, 1994).

Tables $2 \mathrm{a}$ and $2 \mathrm{~b}$ illustrate the results of two hierarchical multiple regression analyses for KD and $\mathrm{KC}$ as constituting processes of KS. The hierarchical multiple regression analysis permitted the authors to specify a fixed order of entry for the explanatory variables and to control explicitly for other factors that can simultaneously affect the dependent variable. The main benefit of such a procedure is related to the fact that the resulting relationship can appear different, after the controlling of one or more variable, from the case in which they are neglected (Cohen et al., 2003).

In Table 2a and Table 2b, Model 1 (Step 1) contains the control variables; Model 2 (Step 2) introduces the individual explanatory variables; Model 3 (Step 3) examines the organizational explanatory variables; and Model 4 (Step 4) introduces the technological independent variable. Both tables show an increase in the explanatory power of the model, from Model (Step) 2 to Model (Step) 4. In particular, when moving from Step 2 to Step 4 , the model's predictive power rises considerably: +.12 for knowledge donating and +.22 for knowledge collecting (e.g., Tabachnick and Fidell, 2001).

\subsection{Control variables}

Regarding the control variables, the findings do not show evidence relating to the impact of employees' age and gender on their KS behaviors. The analysis only shows a slightly negative relationship between age and KD in Model 2 that weakens in Models 3 and 4. Thus, in the case that control variables are the only factors coming into play, older employees are found to be less oriented toward donating their knowledge to others. To this extent, it seems that their knowledge is considered a source of status or job security.

The education level and tenure never show statistical significance, either in KD or in KC. The managerial role presents positive significance for KD only in Step 1, while it shows a negative growing effect on knowledge collecting from Step 2 to Step 4.

\subsection{Explanatory variables}

\subsubsection{Individual factors}

Regarding the role played by individual factors, the enjoyment in helping others has a significant and positive effect on both KD and KC, although the magnitude slightly reduces from Step 2 to Step 4, when organizational and technological factors are considered. Knowledge self-efficacy, instead, appears to be positive and significant for both KD and KC, mostly in Step 2. Therefore, overall, $\mathrm{Hp} 1 \mathrm{a}$ and $\mathrm{Hp} 2 \mathrm{a}$ are supported.

The analysis of the organizational enablers shows that, in general, they positively support KS processes. More precisely, while operating procedures have a weak and not very significant effect, the existence of supportive leadership is significantly positive for both KD and KC. That implies that supportive leadership is able to create the conditions of "work facilitation" recalled by House (1996). Despite studying knowledge collecting, the statistical significance of the organic structure disappears in the final model (see Table 2b, Model 4); given the full significance shown in Model 3, it can be said that the empirical analysis provides support for both $\mathrm{Hp} 1 \mathrm{~b}$ and $\mathrm{Hp} 2 \mathrm{~b}$.

\subsubsection{Organic structure}

The existence of an organic structure has minor, limited positive significance for KC (Step 3), while it is positive and very significant for KD. Such asymmetry confirms that KS and KD have different natures and are expected to be influenced by different factors (Van den Hoof and de Ridden, 2004). In fact, the features of the organic structure are more relevant when the process of voluntary donation to others is considered 
rather than asking others for information. A possible explanation can be drawn from the idea of perceived locus of control (Gagné and Deci, 2005). In fact, the weaker formalization of roles and the horizontal orientation of the coordination mechanisms could make the individuals (in need of help) feel threatened by actions that could undermine their acquired status and enacted role. It is important to underline that the effect of the organic structure is very similar to the one of enjoyment in helping others in KD.

\subsubsection{Technological factors}

The analysis of the technological factors shows that ICT use does not affect KS, while the existence of effective ICT tools and solutions (efficacy) has a positive effect on collecting and a less significant effect on donating knowledge. This evidence seems to show that the availability of ICT solutions for knowledge management enables individuals to search for and retrieve explicit knowledge that has previously been stored by somebody else. In this sense, ICT efficacy could crowd out the interpersonal KS even within organic organizations. Conversely, even the availability of effective ICT solutions cannot ease the process of codifying tacit knowledge or recombining pieces of explicit knowledge. Finally, the results of the F-tests

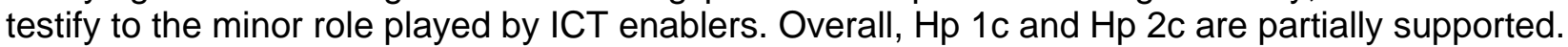

INSERT TABLE 1a ABOUT HERE

INSERT TABLE $1 b$ ABOUT HERE

INSERT TABLE 2a ABOUT HERE

INSERT TABLE 2b ABOUT HERE

\section{Discussion}

The findings confirm all three sets of hypotheses formulated in the research model. Below the authors provide a discussion of each type of variable investigated in this study.

\subsection{Individual enablers}


As shown by the regression analysis, the power of the enjoyment in helping others prevails on knowledge self-efficacy when it comes to understanding the determinants of KS processes. In fact, despite the fact that they both positively push toward KS, altruism, as a personal trait, affects the voluntary donation of knowledge more importantly than the concern for one's agenda. This evidence confirms the importance of considering the intrinsic factors and the related intrinsic benefits driving workers' behaviors within organizations (see, for instance, Lin, 2007). Hence, enjoyment in helping others is considered to be an extra-role behavior - more specifically, a critical component of citizenship behavior (Smith et al., 1983) which, by definition identifies a discretionary act. By conceptually distinguishing the behavior of voluntarily helping others with, or preventing the occurrence of, work-related problems (Podsakoff et al., 2000), enjoyment in helping others plays a critical role in the actions that people take with regard to sharing what they know with others.

In turn, knowledge self-efficacy positively and similarly influences both KS processes, despite its power being reduced when organizational and technological factors are also considered.

\subsection{Organizational enablers}

As can be seen from Table $2 a$ and Table $2 b$, organizational factors positively support KS. However, when compared with each other, their roles appear to be quite different. Indeed, while a supporting leadership style as well as operating procedures influence knowledge donating and knowledge collecting almost equally, providing the firm with an organic structure has dissimilar consequences. For KD, it has a strong and positive effect even when technological factors are added to the analysis, thus supporting the idea that its role is solid as it holds with the whole model too. Conversely, the data show that an organic structure facilitates KC processes in a less significant way than KD processes. Moreover, its statistical power disappears in the final model, that is, when ICT variables are included in the analysis. This indicates that an organic structure affects the two KS sub-processes in different ways, being an imperative for fostering KD behaviors while marginally influencing KC. This argument sheds further light on the importance of considering the two KS processes as separate and independent dimensions.

\subsubsection{Leadership style}

Additionally, among the organizational enablers taken into account in this study, with regard to $\mathrm{KC}$, the leadership style prevails in design features (structure and procedures), providing confirmation that the creation of a culture of KS could be more effective than any structural solution. This suggests the idea that, resulting from an explicit request, KC behaviors hide employees' tendency to contribute to KS only in the case that they are asked to do so. Therefore, KC plays the most significant role when it is sustained by a leadership style that emphasizes subordinates' needs and preferences, as well as the creation of a friendly work environment. Among the organizational variables investigated, leadership style is the one that plays the most significant role. Overall, the enactment of "work facilitation" seems to generate spontaneous donating and critical collecting.

\subsubsection{Operating procedures}

When operating procedures are in place, both $\mathrm{KD}$ and $\mathrm{KC}$ are fostered. Hence, when organizations aim to provide coordinating tools for their employees' behaviors by implementing rules and procedures on the job, this positively affects both KS processes. This evidence recalls the positive side of bureaucracy proposed by Adler and Borys (1996). In particular, they argue that job design features can be experienced as a cooperative endeavor instead of an abrogation of autonomy (p. 63). In so doing, they stress that welldesigned procedures facilitate task performance and increase employees' pride in workmanship by reducing task ambiguity and, consequently, job stress. Consistent with this, it can be expected that clearly defining tasks by rules would help people to organize their knowledge better and thus to be more efficient in participating in $\mathrm{KS}$ processes. 


\subsection{Technological enablers}

Following the results, ICT use does not seem, per se, to be an enabler of KS behaviors. Rather, the perceptions that employees develop around its effectiveness may affect their actual behaviors in terms of contributing or not to KS activities within the firm. Hence, such a perception (i.e., ICT efficacy) significantly helps to increase both knowledge-donating and knowledge-collecting behaviors, meaning that the more people believe ICT is useful for connecting different parts of the organization as well as for supporting internal knowledge flows, the more they will participate in KS with colleagues. This is consistent with the recent findings by Bharati et al. (2015), according to which technology (e.g., social media) has a direct effect upon structural capital and cognitive capital, but it affects relational capital only indirectly (via structural and cognitive capital). Interestingly, its impact is stronger for KC than for KD. The findings of the empirical analysis seem to suggest that, as for $\mathrm{KC}$, while an organic structure does not play a significant role, ICT efficacy is highly effective, thereby providing relevant support for facilitating knowledge-collecting behaviors.

\section{Conclusion}

\subsection{Brief summary of the paper's findings}

Building on the literature about the importance of taking into account individual, organizational and technological factors for KS (Lin, 2007; Van den Hooff and De Ridder, 2004), this research is an attempt to contribute to the understanding of how knowledge-intensive companies can establish a successful KS strategy. After analyzing a sample of 23 knowledge-intensive and international manufacturing firms, the results show the strong value of enjoyment in helping others and a supportive leadership style to sustain KS among employees. Moreover, the data provide evidence that the development of a KS culture is more likely within organic organizations (Burns and Stalker, 1961). In addition, the empirical analysis suggests that organizational enablers explain a great amount of what is needed to foster intra-firm KS. In fact, when included in the regression, the $\mathrm{R}^{2}$ significantly increases concerning both $\mathrm{KD}$ and $\mathrm{KC}$.

\subsection{Limitations of the research and findings}

The paper did not consider all the potential enablers that are critical for KS. Amongst them all, the authors explicitly chose to exclude reward systems as well as the effects of intrinsic motivation from the analysis, given their ambiguous effects on spontaneous behaviors and the documented crowding-out effects (e.g., Bock et al., 2005; O'Dell and Grayson, 1998). Furthermore, given the focus on a specific industry (i.e., manufacturing firms), the findings cannot easily be generalized. A further aspect that is relevant to KS is the physical layout of the spaces in which people interact; that factor was also excluded from the analysis considering the non-verifiability of the information reported via the web survey. Finally, because the data collection was limited to organizations operating in a highly specific area (i.e., Central Italy), the findings are probably not applicable to firms in different national cultures (Bock et al., 2005; Hofstede, 1991).

\subsection{Implications for practitioners and researchers}

This study also provides significant implications for both managers and researchers. Such implications address to both "arm-length" and wider levels of intervention.

\subsection{1 "Arm-length" implications}

The study highlights a potential drawback resulting from longer-tenured employees, as they are negatively oriented toward donating their knowledge to colleagues. Managers should pay attention to this aspect by 
carefully planning their human resource management practices accordingly. For instance, it may be important to create a work environment in which people with longer tenure can be considered critical sources of expertise that others can consult for advice and help. A cooperative and trust-based rather than a competitive work climate can contribute to the establishment of such an environment.

Further, in order to encourage KD, managers need to consider the strong role played by the individual and organizational enablers examined in this study. In particular, it is important to make sure that workers enjoy their job and build tough confidence in their skills and abilities. In this regard, empowerment programs may provide a relevant contribution while valuing workers' satisfaction, development and personal growth.

\subsubsection{Wider implications}

$\mathrm{KC}$ requires managers and researchers to promote a culture such that superiors participate in both donating and asking for knowledge, thus disseminating a feeling of mutual cooperation and fostering their exchange ideology. If managers show a negative orientation toward sharing knowledge upon request, their employees will try to replicate this behavior. Training programs involving both managers and employees may be useful to remove this resistance.

Further, investing in technology to foster intra-organizational KS may not be enough. Beyond that, it is important to make sure that the other two categories of enablers (i.e., organizational and individual) are managed and nourished. Hence, mutual cooperation and interaction are enacted more by individual traits and leadership styles than by ICT procurement. In particular, it was found that organizations should provide their staff with leaders who are able to support, coach and assist, instead of controlling their subordinates. This is because sharing knowledge with others necessarily calls for the consideration of soft antecedents, such as personal traits and lateral integrative mechanisms.

To conclude, consistent with the literature (Cavaliere and Lombardi, 2015; Van de Hooff and de Ridder, 2004), the results confirm that the two KS sub-processes may be affected by different variables and, accordingly, should be investigated separately and independently from each other. The findings presented here encourage a more detailed investigation into further differences that characterize KD and KC.

\subsection{Possible areas for future research}

Future research could take into account other factors, such as further demographic determinants (i.e., career stage) or natural barriers (i.e., time and space) to improve the understanding of intra-organizational KS. Building on structural holes theory, the same data could be used to test how employees' position within the company influences their ability to share knowledge. This is consistent with the role played by boundary spanners (Cohen and Levinthal, 1990), who can bridge disconnected individuals, allowing different types of knowledge to be exchanged more effectively (Ahuja, 2000). Moreover, following Wang and Noe's review of KS research (2010), there is a need to seek objective measures of KS, via the consideration, for instance, of third-party and archival data or the new evidence available via Big Data analytics.

The authors of this paper also agree with colleagues calling for more qualitative research focused on specific issues. In fact, this study could benefit from face-to-face interviews as well as from direct observations both of managers and of employees to deepen the comprehension about the findings resulting from this empirical work.

\subsection{Concluding remarks}

To rule out alternative causal explanations about the results that emerged in the relationship between individual factors, leadership styles and knowledge collecting and to support the internal validity, scholars suggest considering the influence of potential moderators such as personality or contextual conditions (Wang and Noe, 2010). Finally, KD captures various levels of social complexity (e.g., Hughes, 1958), even within the perimeter of the same firm. Further analyses can be conducted by proposing a multi-level approach (e.g., Hackman, 2003; Klein and Kozlowski, 2000; Ostroff and Bowen, 2000; Sveningsson and 
Alvesson, 2003; Van Veldhoven and Dorenbosch, 2008), with the identification of the macro-level (company strategy, organizational form), meso-level (organizational unit: coordination mechanisms) and micro-level (individuals).

Since the relationship between KS and its predictors offers an extremely viable and interesting opportunity for identifying new research directions, the authors of this paper encourage other colleagues to deepen their understanding of this research field. 


\section{References}

Adler, P.S. and Borys, B. (1996), "Two types of bureaucracy: enabling and coercive", Administrative Science Quarterly, Vol. 41 No. 1, pp. 61-89.

Ahuja, G. (2000), "Collaboration networks, structural holes, and innovation: a longitudinal study, Administrative Science Quarterly, Vol. 45 No. 3, pp. 425-455.

Alavi, M. and Leidner, D.E. (2001), "Knowledge management and knowledge management systems: conceptual foundations and research issues", MIS Quarterly, Vol. 25, pp. 107-136.

Alvesson, M. (1993), "Organizations as rhetoric: knowledge-intensive firms and the struggle with ambiguity", Journal of Management Studies, Vol. 30 No. 6, pp. 997-1015.

Ardichvili, A., Page, V. and Wentling, T. (2003), "Motivation and barriers to participation in virtual knowledgesharing communities of practice", Journal of Knowledge Management, Vol. 7 No. 1, pp. 64-77.

Armbrecht, F.M., Chapas, R.B., Chappelow, C.C., Farris, G.F., Friga, P.N., Hartz, C.A., Mcilvaine, M.E., Postle, S.R. and Whitwell, G.E. (2001), "Knowledge management in research and development", ResearchTechnology Management, Vol. 44 No. 4, pp. 28-48.

Armistead, C. (1999), "Knowledge management and process performance", Journal of Knowledge Management, Vol. 3, pp. 143-157.

Arnold, J.A., Arad, S., Rhoades, J.A. and Drasgow, F. (2000), "The empowering leadership questionnaire: the construction and validation of a new scale for measuring leader behaviors", Journal of Organizational Behavior, Vol. 21 No. 3, pp. 249-269.

Aulawi, H., Sudirman, I., Suryadi, K. and Govindaraju, R. (2009), "Knowledge sharing behavior, antecedents and their impact on the individual innovation capability", Journal of Applied Sciences Research, Vol. 5 No. 12, pp. 2238-2246.

Avgerou, C., Ciborra, C. and Land, F. (2004), The Social Study of ICT: Innovation, Actors and Contexts, Oxford University Press, Oxford, UK.

Bandura, A. (1997), Self-efficacy: The Exercise of Control, Freeman, New York.

Barney, J. (1991), "Firm resources and sustained competitive advantage", Journal of Management, Vol. 17 No. 1, pp. 99-120.

Bartol, K.M. and Srivastava, A. (2002), "Encouraging knowledge sharing: the role of organizational reward systems", Journal of Leadership \& Organizational Studies, Vol. 9 No. 1, pp. 64-76.

Bharati, P., Zhang, W. and Chaudhury, A. (2015), "Better knowledge with social media? Exploring the roles of social capital and organizational knowledge management", Journal of Knowledge Management, Vol. 19 No. 3, in press.

Bhatt, G.D. (2001), "Knowledge management in organizations: examining the interaction between technologies, techniques, and people", Journal of Knowledge Management, Vol. 5 No. 1, pp. 68-75.

Bock, G.W. and Kim, Y.-G. (2002), "Breaking the myths of rewards: an exploratory study of attitudes about knowledge sharing", Information Resources Management Journal, Vol. 15 No. 2, pp. 14-21.

Bock, G.-W., Zmud, R.W., Kim, Y.-G. and Lee, J.-N. (2005), "Behavioral intention formation in knowledge sharing: examining the roles of extrinsic motivators, social-psychological forces, and organizational climate", MIS Quarterly, Vol. 29 No. 1, pp. 87-111.

Boland Jr., R.J., Tenkasi, R.V. and Te'eni, D. (1994), "Designing information technology to support distributed cognition", Organization Science, Vol. 5, pp. 456-475.

Brown, J.S. and Duguid, P. (1991), "Organizational learning and communities-of-practice: toward a unified view of working, learning, and innovation", Organization Science, Vol. 2 No. 1, pp. 40-57.

Burns, T. and Stalker, G.M. (1961), The Management of Innovation, Tavistock, London, UK. 
Burton, R.M. and Obel, B. (2004), Strategic Organizational Diagnosis and Design: The Dynamics of Fit, 3rd ed., Springer, New York.

Cabrera, A., Collins, W.C. and Salgado, J.F. (2006), "Determinants of individual engagement in knowledge sharing", International Journal of Human Resource Management, Vol. 17 No. 2, pp. 245-264.

Cao, Y. and Xiang, Y. (2012), "The impact of knowledge governance on knowledge sharing", Management Decision, Vol. 50 No. 4, pp. 591-610.

Cascio, W.F. (2012), "Methodological issues in international HR management research", International Journal of Human Resource Management, Vol. 23 No. 12, pp. 2532-2545.

Cavaliere, V. and Lombardi, S. (2015), "Exploring different cultural configurations: how do they affect subsidiaries' knowledge sharing behaviors?", Journal of Knowledge Management, Vol. 19 No. 2, pp. 141163.

Chang, C.L.H. and Lin, T.C. (2015), "The role of organizational culture in the knowledge management process", Journal of Knowledge Management, Vol. 19 No. 3, in press.

Chang, W.C. and Li, S.T. (2007), "Fostering knowledge management deployment in R\&D workspaces: a five-stage approach", R\&D Management, Vol. 37 No. 5, pp. 479-493.

Cohen, J., Cohen, P., West, S.G. and Aiken, L.S. (2003), Applied Multiple Regression/Correlation Analysis for the Behavioral Sciences, 3rd ed., Lawrence Erlbaum Associates, Mahwah, NJ.

Cohen, W.M. and Levinthal, D.A. (1990), "Absorptive capacity: a new perspective on learning and innovation", Administrative Science Quarterly, Vol. 35, pp. 128-152.

Creed, W.E. and Miles, R.E. (1996), "Trust in organizations: a conceptual framework linking organizational forms, managerial philosophies and the opportunity costs of controls", in Kramer, R.M. and Tyler, T.R. (Ed.), Trust in Organizations: Frontiers of Theory and Research, Sage, Thousand Oaks, CA, pp. 16-38.

Cummings, J.N. (2004), "Work groups, structural diversity, and knowledge sharing in a global organization", Management Science, Vol. 50 No. 3, pp. 352-364.

Davenport, T. and Prusak, L. (1998), Working Knowledge: How Organizations Manage What They Know, Harvard Business School Press, Cambridge, MA.

De Long, D.W. and Fahey, L. (2000), "Diagnosing cultural barriers to knowledge management", Academy of Management Executive, Vol. 14, pp. 113-127.

Deci, E.L. and Ryan, R.M. (1985), Intrinsic Motivation and Self-Determination in Human Behavior, Springer Science \& Business Media, New York.

Deci, E.L. and Ryan, R.M. (2000), “The 'what' and 'why' of goal pursuits: human needs and the selfdetermination of behavior", Psychological Inquiry, Vol. 11 No. 4, pp. 227-268.

Del Giudice, M., Della Peruta, M.R. and Maggioni, V. (2015), "A model for the diffusion of knowledge sharing technologies inside private transport companies", Journal of Knowledge Management, Vol. 19 No. 3 , forthcoming.

Evanschitzky, H., Ahlert, D., Blaich, G. and Kenning, P. (2007), "Knowledge management in knowledgeintensive service networks: a strategic management approach", Management Decision, Vol. 45 No. 2, pp. 265-283.

Fishbein, M. and Ajzen, I. (1975), Belief, Attitude, Intention, and Behavior: An Introduction to Theory and Research, Addison-Wesley, Reading, MA.

Foss, N.J., Husted, K. and Michailova, S. (2010), "Governing knowledge sharing in organizations: levels of analysis, governance mechanisms, and research directions", Journal of Management Studies, Vol. 47 No. 3, pp. 455-482.

Gagné, M. (2009), “A model of knowledge-sharing motivation”, Human Resource Management, Vol. 48 No. 4, pp. 571-589. 
Gagné, M. and Deci, E.L. (2005), "Self-determination theory and work motivation”, Journal of Organizational Behavior, Vol. 26 No. 4, pp. 331-362.

Galbraith, J.R. (1974), “Organization design: an information processing view", Interfaces, Vol. 4 No. 3, pp. 28-36.

Giustiniano, L. and Bolici, F. (2012), "Organizational trust in a networked world: analysis of the interplay between social factors and information and communication technology", Journal of Information, Communication and Ethics in Society, Vol. 10 No. 3, pp. 187-202.

Gold, A.H., Malhotra, A. and Segars, A.H. (2001), "Knowledge management: an organizational capabilities perspective", Journal of Management Information Systems, Vol. 18 No. 1, pp. 185-214.

Grant, R.M. (1996), "Toward a knowledge-based theory of the firm”, Strategic Management Journal, Vol. 17 (Winter Special Issue), pp. 109-122.

Grodal, S., Nelson, A.J. and Siino, R.M. (2015), "Help-seeking and help-giving as an organizational routine: continual engagement in innovative work", Academy of Management Journal, Vol. 58 No. 1, pp. 136-168.

Gupta, A.K. and Govindarajan, V. (2000), "Knowledge flows within multinational corporations", Strategic Management Journal, Vol. 21, pp. 473-496.

Hackman, J.R. (2003), "Learning more by crossing levels: evidence from airplanes, hospitals, and orchestras", Journal of Organizational Behavior, Vol. 24 No. 8, pp. 905-922.

Hackman, J.R. and Oldham, G.R. (1974), The Job Diagnostic Survey. An Instrument for the Diagnosis of Jobs and the Evaluation of Job Redesign Projects, Yale University, New Haven, CT.

Håkonsson, D.D., Burton, R.M., Obel, B. and Lauridsen, J.T. (2012), "Strategy implementation requires the right executive style: evidence from Danish SMEs", Long Range Planning, Vol. 45 No. 2, pp. 182-208.

Hansen, M.T. (1999), "The search-transfer problem: the role of weak ties in sharing knowledge across organization subunits", Administrative Science Quarterly, Vol. 44, pp. 82-111.

Hargadon, A.B. (1998), "Firms as knowledge brokers: lessons in pursuing continuous innovation”, California Management Review, Vol. 40, pp. 209-227.

Hofstede, G. (1991), Cultures and Organizations: Software of the Mind, McGraw-Hill, New York.

House, R.J. (1996), "Path-goal theory of leadership: lessons, legacy, and a reformulated theory", Leadership Quarterly, Vol. 7 No. 3, pp. 323-352.

House, R.J. (1971), "A path-goal theory of leader effectiveness", Administrative Science Quarterly, Vol. 16 No. 3, pp. 321-338.

House, R.J. and Mitchell, T.R. (1974), "Path-goal theory of leadership", Journal of Contemporary Business, Vol. 3, pp. 81-97.

Hughes, E.C. (1958), Men and Their Work, The Free Press of Glencoe, Glencoe, IL.

Huysman, M. and Wulf, V. (2006), "IT to support knowledge sharing in communities: towards a social capital analysis", Journal of Information Technology, Vol. 21 No. 1, pp. 40-51.

Hwang, Y., Kettinger, W.J. and Mun, Y.Y. (2014), "Personal information management effectiveness of knowledge workers: conceptual development and empirical validation", European Journal of Information Systems. doi: 10.1057/ejis.2014.24.

IRPET - Regional Institute, Planning Economic of Tuscany (2014), available at: http://www.irpet.it/en/index.php (accessed 18 December 2014).

Jarle Gressgård, L., Amundsen, O., Merethe Aasen, T. and Hansen, K. (2014), "Use of information and communication technology to support employee-driven innovation in organizations: a knowledge management perspective", Journal of Knowledge Management, Vol. 18 No. 4, pp. 633-650. 
Jeon, S., Kim, Y.-G. and Koh, J. (2011), "An integrative model for knowledge sharing in communities-ofpractice", Journal of Knowledge Management, Vol. 15 No. 2, pp. 251-269.

Judge, T.A. and Bono, J.E. (2001), "Relationship of core self-evaluation traits-self-esteem, generalized self-efficacy, locus of control, and emotional stability-with job satisfaction and job performance: a metaanalysis", Journal of Applied Psychology, Vol. 86 No. 1, pp. 80-92.

Kaiser, S., Müller-Seitz, G., Lopes, M.P. and Cunha, M.P. (2007), "Weblog-technology as a trigger to elicit passion for knowledge", Organization, Vol. 14 No. 3, pp. 391-412.

Kim, S. and Lee, H. (2006), "The impact of organizational context and information technology on employee knowledge-sharing capabilities", Public Administration Review, Vol. 66 No. 3, pp. 370-385.

Klein, K.J. and Kozlowski, S.W.J. (Eds.) (2000), Multilevel Theory, Research, and Methods in Organizations: Foundations, Extensions, and New Directions, Jossey-Bass, San Francisco, CA.

Kogut, B. and Zander, U. (1992), "Knowledge of the firm, combinative capabilities, and the replication of technology", Organization Science, Vol. 3 No. 3, pp. 383-397.

Lee, H. and Choi, B. (2003), "Knowledge management enablers, processes, and organizational performance: an integrative view and empirical examination", Journal of Management Information Systems, Vol. 20 No. 1, pp. 179-228.

Liao, L.F. (2008), "Knowledge-sharing in R\&D departments: a social power and social exchange theory perspective", International Journal of Human Resource Management, Vol. 19 No. 10, pp. 1881-1895.

Lin, H. (2007), "Knowledge sharing and firm innovation capability: an empirical study", International Journal of Manpower, Vol. 28 No. 3/4, pp. 315-332.

Meeus, M.T.H., Oerlemans, L.A.G. and Hage, J. (2001), "Patterns of interactive learning in a high-tech region", Organization Studies, Vol. 22 No. 1, pp. 145-172.

Mei, Y.M., Lee, S.T. and Al-Hawamdeh, S. (2004), "Formulating a communication strategy for effective knowledge sharing", Journal of Information Science, Vol. 30 No. 1, pp. 12-22.

Miller, D. (1983), "The correlates of entrepreneurship in three types of firms", Management Science, Vol. 29 No. 7, pp. 770-791.

Mintzberg, H. (1979), The Structuring of Organizations, Prentice Hall, Englewood Cliffs, NY.

Nonaka, I. (1991), "The knowledge creating company", Harvard Business Review, Vol. 69, NovemberDecember, pp. 96-104.

O'Dell, C. and Grayson, C. (1998), "If only we knew what we know: identification and transfer of internal best practices”, California Management Review, Vol. 40 No. 3, pp. 154-174.

Organ, D.W. (1988), Organizational Citizenship Behavior: The Good Soldier Syndrome, Lexington Books, Lexington, MA.

Orlikowski, W.J. and Gash, D.C. (1994), "Technological frames: making sense of information technology in organizations", ACM Transactions on Information Systems (TOIS), Vol. 12, pp. 174-207.

Ostroff, C. and Bowen, D.E. (2000), "Moving HR to a higher level: human resource practices and organizational effectiveness", in Klein, K.J. and Kozlowski, S.W.J. (Eds.), Multilevel Theory, Research, and Methods in Organizations, Jossey-Bass, San Francisco, CA, pp. 211-266.

Palvalin, M., Lönnqvist, A. and Vuolle, M. (2013), "Analysing the impacts of ICT on knowledge work productivity", Journal of Knowledge Management, Vol. 17 No. 4, pp. 545-557.

Peterson, R. (1994), "A meta-analysis of Cronbach's coefficient alpha”, Journal of Consumer Research, Vol. 21 No. 2, pp. 381-391.

Pinho, I., Rego, A. and Cunha, M.P. (2012), "Improving knowledge management processes: a hybrid positive approach", Journal of Knowledge Management, Vol. 16 No. 2, pp. 215-242. 
Podsakoff, P.M., MacKenzie, S.B., Paine, J.B. and Bachrach, D.G. (2000), "Organizational citizenship behavior: a critical review of the theoretical and empirical literature and suggestions for future research", Journal of Management, Vol. 26 No. 3, pp. 513-563.

Polanyi, M. (1958), Personal Knowledge: Towards a Post-Critical Philosophy, Routledge, London, UK.

Porter, M.E. and Millar, V.E. (1985), "How information gives you competitive advantage", Harvard Business Review, July-August, pp. 149-160.

Quigley, N.R., Tesluk, P.E., Locke, E.A. and Bartol, K.M. (2007), "A multilevel investigation of the motivational mechanisms underlying knowledge sharing and performance", Organization Science, Vol. 18 No. 1, pp. 71-88.

Quinn, J.B., Anderson, P. and Finkelstein, S. (1996), "Leveraging intellect", Academy of Management Executive, Vol. 10 No. 3, pp. 7-27.

Rechberg, I.D.W. and Syed, J. (2014), "Appropriation or participation of the individual in knowledge management", Management Decision, Vol. 52 No. 3, pp. 426-445.

Rego, A., Pinho, I., Pedrosa, J. and Cunha, M.P.E. (2009), "Barriers and facilitators to knowledge management in university research centers: an exploratory study", Management Research: The Journal of the Iberoamerican Academy of Management, Vol. 7 No. 1, pp. 33-47.

Reid, F. (2003), "Creating a knowledge sharing culture among diverse business units", Employment Relations Today, Vol. 30 No. 3, pp. 43-49.

Ruggles, R. (1998), "The state of the notion: knowledge management in practice", California Management Review, Vol. 40 No. 3, pp. 80-89.

Schroer, J. and Hertel, G. (2009), "Voluntary engagement in an open web-based encyclopedia: Wikipedians and why they do it", Media Psychology, Vol. 12 No. 1, pp. 96-120.

Serenko, A. and Dumay, J. (2015), "Citation classics published in knowledge management journals. Part I: articles and their characteristics", Journal of Knowledge Management, Vol. 19 No. 2, pp. 401-431.

Sheng, M.L., Chang, S.Y., Teo, T. and Lin, Y.F. (2013), "Knowledge barriers, knowledge transfer, and innovation competitive advantage in healthcare settings", Management Decision, Vol. 51 No. 3, pp. 461-478.

Smith, C.A., Organ, D.W. and Near, J.P. (1983), "Organizational citizenship behavior: its nature and antecedents", Journal of Applied Psychology, Vol. 68 No. 4, pp. 653-663.

Spector, P.E. (1985), "Measurement of human service staff satisfaction: development of the Job Satisfaction Survey", American Journal of Community Psychology, Vol. 13 No. 6, pp. 693-713.

Spector, P. (1994), "Using self-report questionnaires in OB research: a comment on the use of a controversial method", Journal of Organizational Behavior, Vol. 15 No. 5, pp. 385-392.

Spreitzer, G.M. (1995), "Psychological empowerment in the workplace: dimensions, measurement, and validation", Academy of Management Journal, Vol. 38 No. 5, pp. 1442-1465.

Srivastava, A., Bartol, K.M. and Locke, E.A. (2006), "Empowering leadership in management teams: effects on knowledge sharing, efficacy, and performance", Academy of Management Journal, Vol. 49 No. 6, pp. 1239-1251.

Staats, B.R., Brunner, D.J. and Upton, D.M. (2011), "Lean principles, leaning, and knowledge work: evidence from a software services provider", Journal of Operations Management, Vol. 29 No. 5, pp. 376390.

Starbuck, W.H. (1992), "Learning by knowledge-intensive firms", Journal of Management Studies, Vol. 29 No. 6, pp. 713-740.

Stenius, M., Hankonen, N., Haukkala, A. and Ravaja, N. (2015), "Understanding knowledge sharing in the work context by applying a belief elicitation study", Journal of Knowledge Management, Vol. 19 No. 3, forthcoming. 
Sun, P. (2010), "Five critical knowledge management organizational themes", Journal of Knowledge Management, Vol. 14 No. 4, pp. 507-523.

Sveningsson, S. and Alvesson, M. (2003), "Managing managerial identities: organizational fragmentation, discourse and identity struggle", Human Relations, Vol. 56 No. 10, pp. 1163-1193.

Swan, J., Newell, S., Scarbrough, H. and Hislop, D. (1999), "Knowledge management and innovation: networks and networking", Journal of Knowledge Management, Vol. 3 No. 4, pp. 262-275.

Tabachnick, B.G. and Fidell, L.S. (2001), Multivariate Statistics, Allyn \& Bacon, Needham Heights, MA.

Thompson, A. (2005), "Creating need-to-have portals: addressing the real-world barriers at KBR Production Services", Knowledge Management Review, Vol. 8 No. 4, pp. 24-28.

Van Baalen, P., Bloemhor-Ruwaard, J. and Van Heck, E. (2005), "Knowledge sharing in an emerging network of practice: the role of a knowledge portal", European Management Journal, Vol. 23, pp. 300-314.

Van den Hooff, B. and de Leeuw van Weenen, F. (2004), "Committed to share: commitment and CMC use as antecedents of knowledge sharing", Knowledge and Process Management, Vol. 11 No. 1, pp. 13-24.

Van den Hooff, B. and de Ridder, J.A. (2004), "Knowledge sharing in context: the influence of organizational commitment, communication climate and CMC use on knowledge sharing", Journal of Knowledge Management, Vol. 8 No. 6, pp. 117-130.

Van den Hooff, B. and Huysman, M. (2009), "Managing knowledge sharing: emergent and engineering approaches", Information \& Management, Vol. 46 No. 1, pp. 1-8.

Van Dyne, L. and LePine, J.A. (1998), "Helping and voice extra-role behaviors: evidence of construct and predictive validity", Academy of Management Journal, Vol. 41 No. 1, pp. 108-119.

Van Veldhoven, M. and Dorenbosch, L. (2008), “Age, proactivity and career development", Career Development International, Vol. 13 No. 2, pp. 112-131.

Vorakulpipat, C. and Rezgui, Y. (2008), "An evolutionary and interpretive perspective to knowledge management", Journal of Knowledge Management, Vol. 12 No. 3, pp. 17-34.

Wang, S. and Noe, R.A. (2010), "Knowledge sharing: a review and directions for future research", Human Resource Management Review, Vol. 20, pp. 115-131.

Wasko, M.M. and Faraj, S. (2000), "It is what one does: why people participate and help others in electronic communities of practice", Journal of Strategic Information Systems, Vol. 9, pp. 155-173.

Wasko, M.M. and Faraj, S. (2005), "Why should I share? Examining social capital and knowledge contribution in electronic networks of practice”, MIS Quarterly, Vol. 29 No. 1, pp. 35-57.

Willem, A. and Scarbrough, H. (2006), "Social capital and political bias in knowledge sharing: an exploratory study", Human Relations, Vol. 59 No. 10, pp. 1343-1370.

Witherspoon, C.L., Bergner, J., Cockrell, C. and Stone, D.N. (2013), "Antecedents of organizational knowledge sharing: a meta-analysis and critique", Journal of Knowledge Management, Vol. 17 No. 2, pp. 250-277.

Womack, J.P, Jones, D.T. and Roos, D. (1990), The Machine that Changed the World, Rawson Associates, Macmillan Publishing, New York, NY.

Yeh, Y.J., Lai, S.Q. and Ho, C.T. (2006), "Knowledge management enablers: a case study", Industrial Management \& Data Systems, Vol. 106, pp. 793-810.

Zack, M.H. (1999), “Managing codified knowledge”, Sloan Management Review, Vol. 40, pp. 45-58.

Zaidman, N. and Brock, D.M. (2009), "Knowledge transfer within multinationals and their foreign subsidiaries: a culture-context approach", Group \& Organization Management, Vol. 34, pp. 297-329.

Zhang, X. and Jiang, J.Y. (2015), "With whom shall I share my knowledge? A recipient perspective of knowledge sharing", Journal of Knowledge Management, Vol. 19 No. 2, pp. 277-295. 